\title{
Systems mapping workshops and their role in understanding medication errors in healthcare
}

\author{
P. Buckle ${ }^{\mathrm{a}, *}$, P.J. Clarkson ${ }^{\mathrm{b}}$, R. Coleman ${ }^{\mathrm{c}}$, J. Bound $^{\mathrm{c}}$, J. Ward $^{\mathrm{b}}$, J. Brown ${ }^{\mathrm{d}}$ \\ ${ }^{a}$ University of Surrey, Guildford GU2 7TE, England, UK \\ ${ }^{\mathrm{b}}$ The Cambridge Engineering Design Centre, University of Cambridge, UK \\ ${ }^{\mathrm{c}}$ The Helen Hamlyn Research Centre, Royal College of Art, London, UK \\ ${ }^{\mathrm{d}}$ Baker Brown Associates, Bristol, UK
}

\section{A R T I C L E I N F O}

\section{Article history:}

Received 30 September 2007

Accepted 15 December 2009

\begin{abstract}
A B S T R A C T
Systems mapping workshops have been applied to the problem of medication errors in healthcare. The workshops were designed using experiential group work principles. They involved a range of stakeholders from within the health service as well as those who supply the health sector, including designers who may be able to enhance the safety of products and systems used in healthcare. Research has shown that the method encourages stakeholder participation, provides robust results within a limited time and enhances understanding across specialist interest groups. Additional, creative design workshops that considered the same topic showed significant promise in developing concepts from which potential solutions could be developed further.
\end{abstract}

(c) 2010 Elsevier Ltd. All rights reserved.

\section{Introduction}

Mapping workshops are one example of a method that ergonomists can use to help generate a knowledge base for better design requirements (Buckle et al., 2006). The opportunity for using these methods to study patient safety issues arose as a result of a scoping study undertaken on behalf of the Department of Health and the Design Council in the UK (Buckle et al., 2003; Cambridge et al., 2004; Clarkson et al., 2004). As the scope of patient safety issues within the healthcare system and the range of stakeholder groups is large (Audit Commission, 2001; Department of Health, 2001 and 2004; National Patient Safety Agency, 2005) it was felt that mapping workshops might enhance system design in the health sector.

\subsection{Origins of the workshop process design}

The Design for Patient Safety (DPS) stakeholder workshops were designed using experiential group work principles. These have their origins in the work of the social psychologist Kurt Lewin and his group relations training methodology called Training-groups (or T-groups). Associates of Lewin (e.g. Bradford et al., 1964) who were involved in the early experiments with T-groups in 1946,

\footnotetext{
* Corresponding author. Tel.: +44 1483689213.

E-mail address: p.buckle@surrey.ac.uk (P. Buckle).
}

described the methodology as follows: "A T-group is a relatively unstructured group in which individuals participate as learners. The data for learning are not outside these individuals or remote from their immediate experience within the T-group. The data are the transactions among members, their own behaviour in the group, as they struggle to create a productive and viable organisation, a miniature society, and as they work to stimulate and support one another's learning within that society."

One of the most important aspects of experiential group work is the distinction between content and process. Miller (1989) described the difference as follows:

"The content of a group refers to what a group is doing, its tasks, while the process refers to how the group task is achieved."

This distinction is central to the functioning of T-groups, especially those which have the objective of learning about group processes. In such contexts, the process becomes the content. This is wholly appropriate when participants have come together to learn about group processes, or about their personal functioning in a group setting. But, as this paper demonstrates, experiential group work techniques can be used to explore other forms of content, in this case patient safety in the NHS.

This application of experiential group work techniques to innovation and design issues grew from the work of both Miller and Brown (e.g. Miller, 1989; Miller and Brown, 1985). Miller and Brown (1985) described the use of this approach in an event called the Mini-economy. The purpose of the Mini-Economy event was to 
explore the economic relationships between people in society, at a time when, in 1985, there was mass unemployment and economic recession. Participants from a broad cross-section of society were recruited, ranging from unemployed people, to senior managers in multinationals.

Subsequent applications of this approach have included an investigation into the future of television broadcasting in the UK (Brown, 1989), the regeneration of neighbourhoods in two towns (Brown, 1996), and product innovation in workers' co-operatives (Brown, 1997.) In each case a group of stakeholders was engaged in an experiential event where a miniature society was established to achieve a common objective. In these events the role of the facilitators was to design and manage the process, allowing the participants to focus on the content. The fact that the facilitators had no expertise in the content meant that they could focus on the process, which in turn enabled the groups to make greater progress with the content. This approach formed the basis for the DPS stakeholder workshops described in this paper.

\subsection{Relevance to medication errors}

In the context of the DPS study, a major challenge was to understand how stakeholders from across the National Health Service (NHS) could become involved in the process of understanding and addressing design and patient safety issues within the context of large and highly complex organisation. More specifically, a focus on 'medication errors and human factor issues' was identified as a priority for investigation. As one part of this study we decided to create (albeit for a relatively short space of time) a miniature, self-reflecting society that could understand itself as a representative sub-set of the entire system, and explore the reality and consequences of interactions between elements of that system.

There were two additional requirements of the stakeholder engagement process. The first requirement was to validate elements of the desk research (see Cambridge, Surrey, RCA 2004), in particular the mapping of the NHS system and the relationship/ interactions between major segments such as primary and secondary care, the regulatory and manufacturing sectors, and specialist services and professions. The second requirement was a) to rapidly capture data on medication-related problems and errors within a system where open reporting is not the norm, and b) to understand, categorise and prioritise these adverse events with regard to their actual and potential impact on patient safety and the safety of the system as a whole.

\section{Patient safety stakeholder workshops}

A series of workshops was held to better understand the challenges facing stakeholders across the healthcare industry, and their priorities and concerns. The primary workshop objectives were to:

1. Map the distribution and delivery of medication within the healthcare system under study from a human factors perspective.

2. Identify problems and sources of medication error.

3. Understand the system from the user perspective and its potential for failure.

4. Find creative 'solutions' that were compatible with a human factor's systems approach to safety.

Medication error has been defined in this study within Cambridge, Surrey, RCA 2004.

\subsection{Overview}

Four workshops were planned to meet these objectives. The participants for these workshops and method used to conduct them are described below.

Their duration and scope took account of the limited availability of potential participants but nevertheless were considered to provide coverage of an appropriate range of stakeholders across the NHS. The first two workshops were full-day, structured events. They were organised for a cross-section of representatives from primary and secondary care services, purchasing and licensing, and equipment and pharmaceutical industries. In addition, a facilitated two hour discussion group session was held with patient group representatives. Finally a fourth, creative workshop was held with a view to developing creative 'solutions' to the problems identified through the earlier workshops.

The experiential group work (see below for the activities conducted) offered a method for probing complex issues within a large and fragmented system. This was achieved through the conducting of the workshops that were combined with an integral data collection mechanism. The latter took the form of the accompanying workbooks and visual aids - maps, diagrams, illustrations and presentations. Thus, a core activity of the experiential group work was the capturing of personal experiences and reflections in the workbooks, and then discussing, clustering and prioritising these through group and plenary sessions to arrive at a shared consensus around key issues, and to identify areas of disagreement and contention. The workbooks were designed to be physically 'deconstructed' over the duration of the workshop, and to capture data in a way that preserved anonymity on the day and for later publication, but allowed for thorough analysis of the 'reconstructed' workbooks after the event, using the forms-based database: FileMaker Pro.

Such activities were also intended to serve the multiple purposes of building a sense of community and co-operation in tackling patient safety; to rapidly capture a substantial body of data; identifying high risk 'hotspots and design challenges'; to flesh out a mapping of the system to incorporate and reflect stakeholder experience; and to begin to think about developing solutions within the context of the larger system.

The data from the first three sessions were analysed and used to inform and focus the final one-day 'creative' workshop. At this creative workshop, the atmosphere was designed to be informal and the event was structured along the lines of 'user forums' and 'brainstorm' sessions, both common working methods within usercentred design research and practice. This encouraged a sense of 'ownership' of problems and challenges, and a genuine commitment to finding solutions. Two research team members were present but no other observers attended, in order to encourage a relaxed and collaborative working atmosphere. Workshops were professionally facilitated and were conducted under rules of confidentiality which participants were asked to sign, in order to encourage openness and the sharing of information and experience.

\subsection{Participants}

Participants were selected using a purposive sampling technique to ensure appropriate coverage of those roles and specialties considered by the research team to be of most help in understanding the system. Participants were contacted directly through a number of practice links. It is recognised that the sample might therefore be subject to bias, particularly in that participants were made aware that the focii of the workshops included identification of medication error. The participants at the first two workshops 
included 20 representatives from across the primary and secondary care sectors (time of service ranged from 8 to 42 years, with an average of 26.9 years) and 17 from procurement, licensing, and the equipment and pharmaceutical industries (professional healthcare related experience ranged from 3 to 45 years, with an average of 23.3 years). Some of the participants held very senior posts and had a lifetime of experience of healthcare services, others were more junior and had more day-to-day contact with patients. Collectively the participants had almost 1000 years of experience, with a range of 3-45 years and an average of 24 years. The patient group comprised four representatives from patient support groups, with the discussion led by the workshop facilitator.

The membership of the creative workshop brought together a sub-set of nine participants from the first three workshops, giving a good spread across the stakeholder groups. There were two industry representatives; the head of a large design group and a product manager, who did not attend the earlier workshops; and seven design professionals, ranging from current and recent Royal College of Art (RCA) graduates to senior designers with experience in a medical context and of major design implementation projects. Between them the designers had over 140 years of experience, ranging from 9 to 37 years, with an average of 24 years.

\subsection{Method for mapping the system}

Each workshop began with a simplified map of the healthcare system, produced by the research team, based on earlier deskbased investigations.

Participants were asked to complete a short personal profile, give some detail on their reasons for attending, and position themselves on the map. Additional elements of the system and relationships were added to the map as requested by the workshop participants.
The map was based on concentric rings with the patient and carer placed at the centre. In the first ring, beginning at the top and moving in a clockwise direction, were: hospital doctor; hospital nurse; community pharmacy; off-the-shelf medication; care house nurses; community nurses and general practitioners. In the next ring were placed: purchasing; hospital pharmacy; ward-stock; pathology and dispensing software. Finally, in the outer ring, were: equipment suppliers; drug companies; trade associations; expert opinion; distribution; government agencies, (including the Medical Devices Agency and Medicines Control Agency that have since been amalgamated, to form the Medicines and Healthcare products Regulatory Agency (MHRA).

Over the course of the two workshops and the patient groups discussion session, the following were added (see Figs. 1 and 2) to the inside ring: patient consent; patient support groups; care providers; occupational therapists; alternative therapists; clinics, in particular diabetes; consultants and emergency rescue and first aid. To the second ring were added: prescribing software; hospital management; equipment training; investigation processes; the hospital environment; and a differentiation was made between purchasing of equipment and medicines. To the outside ring were added: NHS agencies; trade unions and professional bodies; the Internet; government; self-help groups; the research community; device manufacturers; service providers; drug delivery design and buying from drug companies on behalf of community pharmacies. This generated the final map. This map is best described as a 'high level' description of the system. It is therefore of potentially limited use for specific applications. However, as described in the following section, it allowed for all participants to understand relationships between individual system's elements and this also aided their discussions regarding potential failure modes.

However, it is important to recognize that the representatives in the workshops did not cover all the roles subsequently identified

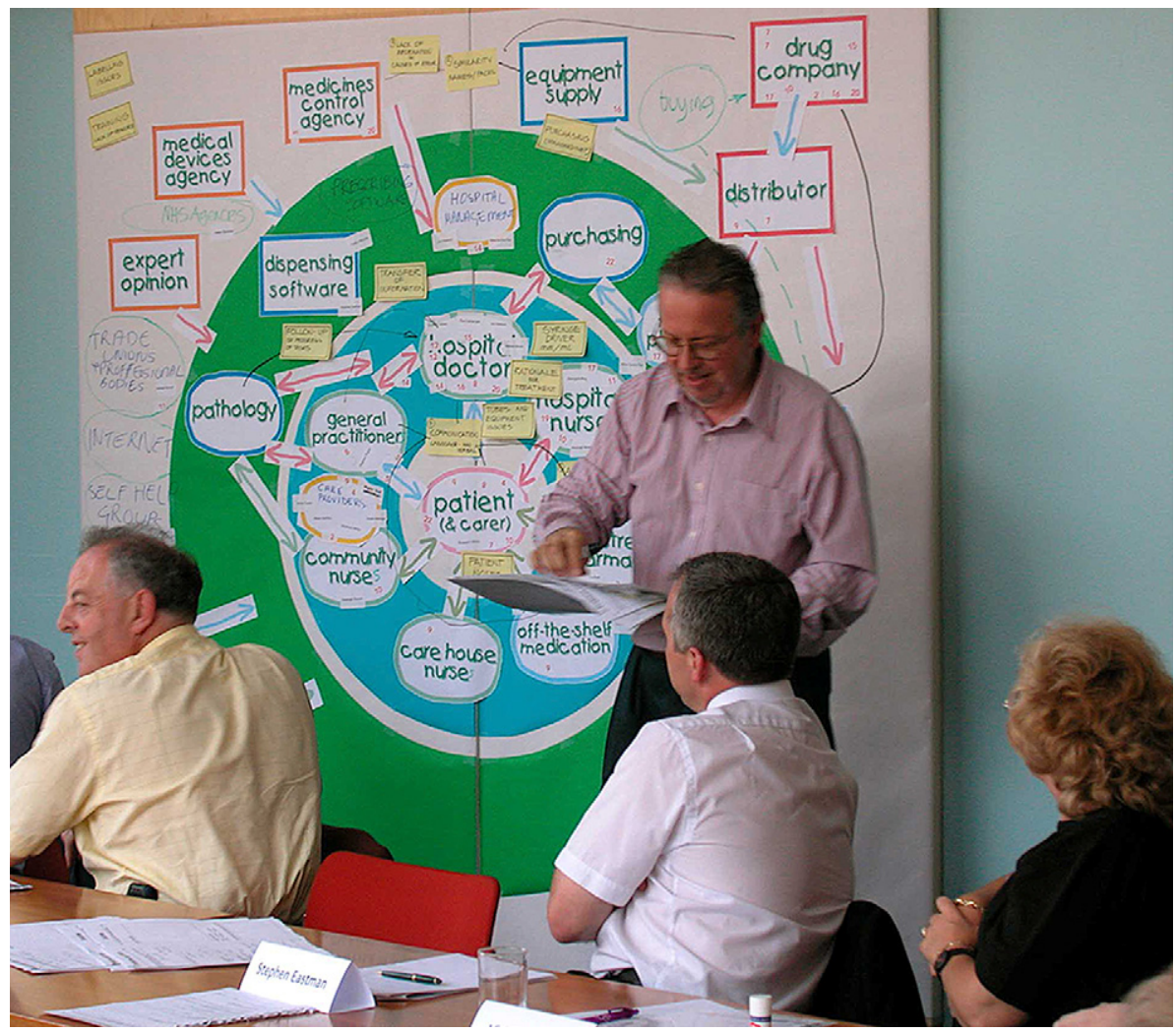

Fig. 1. The mapping workshop. 


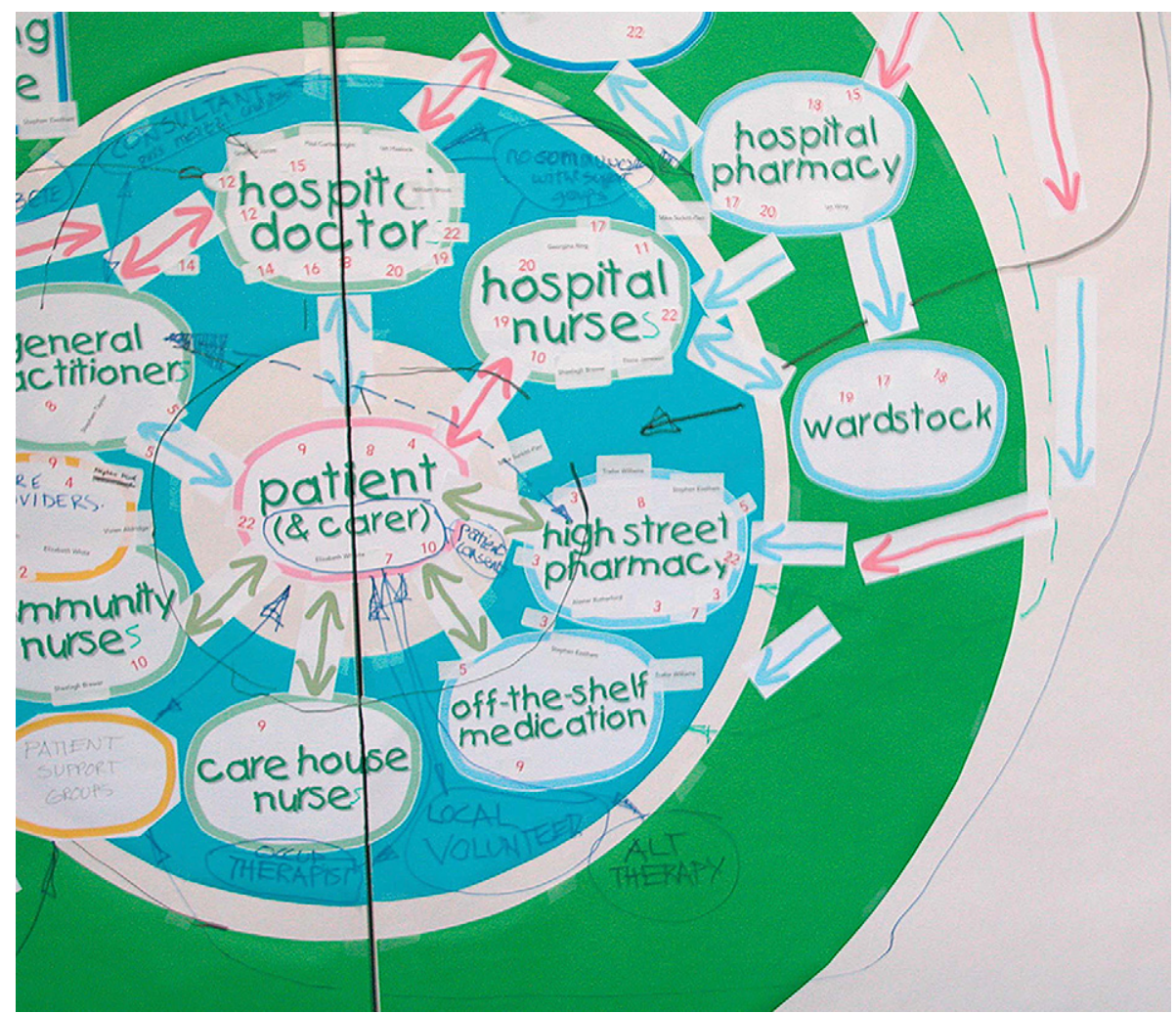

Fig. 2. Development of map.

on the map. Further studies, that include a wider selection of healthcare and other related professionals might now be required to confirm the robustness and validity of the map and subsequent capture of problems and sources of error.

\subsection{Method for capturing problems and sources of error}

The participants were asked to list actual and potential problems/errors and likely causes they were aware of or had direct experience of, and attach markers to the map indicating where these problems/errors were situated within the overall system, thus identifying hotspots for medication error. (see Fig. 3)

After that, meeting in sector-specific groups, the participants prioritised problems/errors, chose the top four problems from each sub-group and presented these back to the full group. At this stage, our earlier research as to potential sources of error based on the contemporary literature were also presented to the full group and marked on the system map. This provided the participants with an opportunity to compare our literature research results with their own, stakeholder, experience.

The participants then split into 2 cross-sector groups and worked on identifying potential solutions and design opportunities to the top eight problems/errors prioritised in the earlier session. These were presented back to the full group in a plenary session, and the workshops concluded with a feedback session that allowed participants to reflect on the day.

\subsection{Method for finding creative 'solutions'}

Key outcomes from the first three workshops were taken to a 'creative' workshop, where designers, with experience of product designing for the healthcare industry, were added to the stakeholder mix. The system-wide nature of the prior workshops did not provide the level of detailed information to underpin complete design solutions. However, there was good reason to believe from other research (O'Brien, 1981; Wilson, 1991)) that similar workshop methods, combining data gathering with community creation, and with a tighter focus, might facilitate requirements capture and generate design solutions to advance patient safety within a complex system such as the NHS.

This workshop was focused on a series of drawings of patientcentred situations/environments that charted the patient journey through the healthcare system, from the home, through the GP surgery or rescue services, to entry to hospital, in-patient treatment and outpatient return to community-based aftercare. The nondesigner participants identified and discussed issues and problems/ challenges in each situation.

The participants were then placed into three mixed groups of two or three designers and three healthcare professionals, plus industry representatives.

More detailed information and mini case studies emerged in the team working sessions that were organised around three simple briefs. Participants were asked to come up with 3 illustrated ideas/ scenarios to patient information/records, pack information/access, or medical devices and drug administration. They were then asked to select one idea to present in depth to the whole group. The team leader introduced how the group approached the brief, where it looked for solutions, and the non-preferred ideas, and another person presented the selected idea. As the team leaders were all designers, this ensured that both designers and non-designers presented back to the assembled group. They worked on the briefs for over two hours, and then presented their conclusions to the full group.

The briefs were purposefully open to encourage maximum sharing of information and discussion of issues, directions and possible solutions. The teams were asked to come up with ideas 


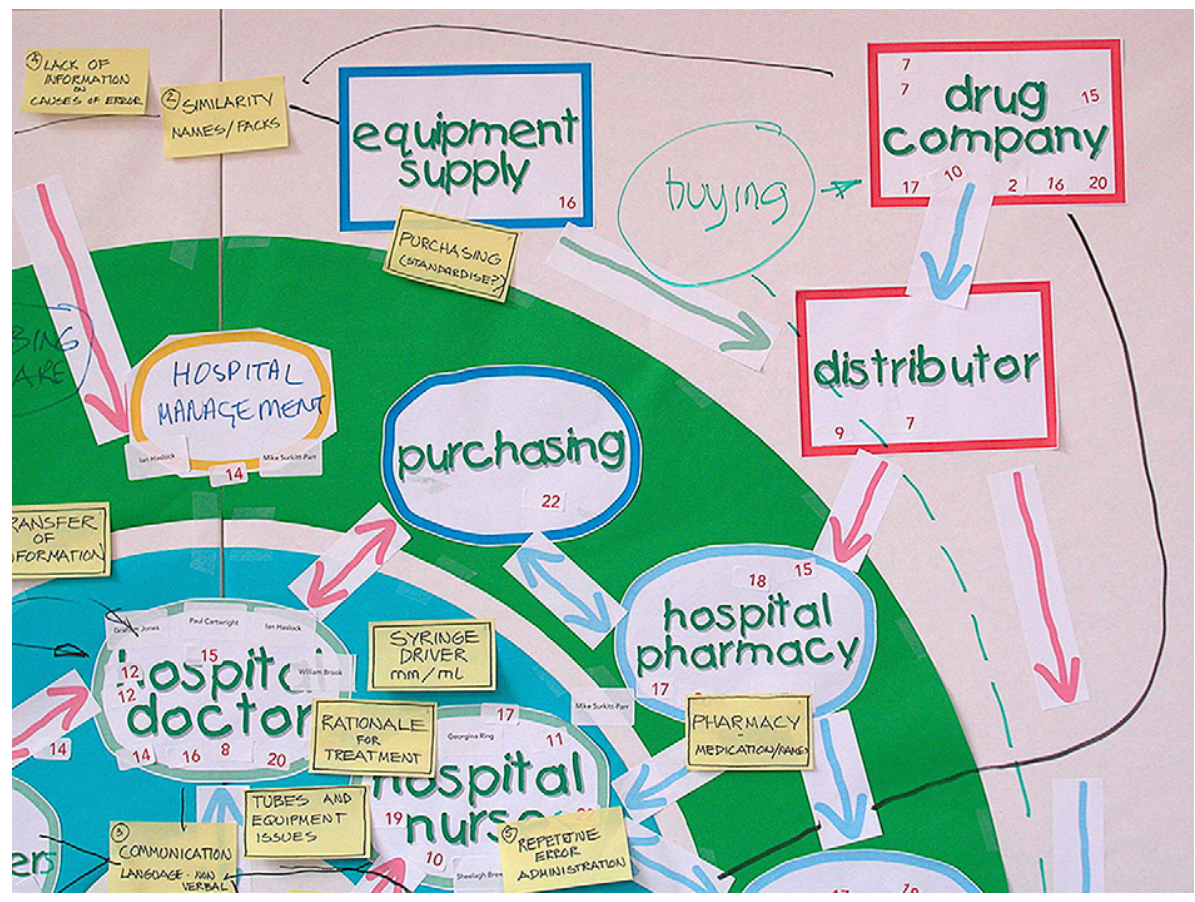

Fig. 3. Mapping sources of error.

and directions rather than specific solutions, and the overall intention was to discover how well the process could work. In normal circumstances, the designers would go on from such an intensive user or 'stakeholder' forum to develop more specific and in-depth solutions, which would then be tested and re-tested with users as part of a process of homing in on and working up the detail of final proposals. There was not time to take the process through to this stage, but in the context of a scoping study that was not thought necessary. Discussion followed during which obstacles and other factors were identified for each of the 'solutions'.

\section{Results}

\subsection{Mapping the system}

In filling out the map of the system the participants added layers of complexity, both in terms of stakeholder groups and the interconnections between them. What emerged was a system whose intricacy surprised the participants and pointed to key underlying problems related to fragmentation, parochialism, and lack of communication and integration. The number and diversity of interfaces between stakeholder groups created opportunities for errors, in particular those associated with information transfer, conflicts of interest, differing protocols and working practices and conflicts of status and seniority. By positioning their problems on the same map, key areas emerged, which helped to identify risky situations and activities, and focus discussion around them.

Consensus was reached on some issues. These included that:

- The National Health Service (NHS) was considered to be a fractured, complex organisation.

- Surprise was registered that the NHS is not more forceful in its purchasing.

- It was felt that mistakes occurred under pressure, and that pressure is endemic in the system.

- Blame culture was seen as a considerable obstacle to change.

- It was felt that there was considerable scope for collaboration and standardisation across sectors.
- Concern was expressed over issues of information, packaging and labelling.

- It was felt that the NHS needs to be innovative in tackling error and patient safety, learn from other industries and take a multidisciplinary approach to this.

However, sectoral differences emerged over other issues. For example, those within primary and secondary care were more aware of specific problems and instances as they experience them, whereas those within industry, purchasing and licensing tended to see the issues in terms of generalities.

Those closest to implementing or specifying solutions had least contact with patients and first hand experience of things going wrong, while those closest to the problems, and patient contact, had the least contact with design and designers. This indicates a considerable opportunity for the capture and transfer of safety-relevant information up the supply chain, and for designers, specifiers and purchasers to learn from end users and those in direct contact with patients.

\subsection{Capturing problems and sources of error}

A significant range and diversity of problems were captured during the workshops, and a wealth of detail exposed in discussion.

The problems could be grouped under the six major headings (see Tables 1-6) of self-medication errors, prescription errors, dispensing errors, administration errors, information and records errors and equipment and devices.

As a result of identifying these problems, a number of major challenges emerged.

a) Around the design of packaging - access to medication, accompanying information, the separation of medication from packaging and information, and correct identification of pack/ contents.

b) Around patient information and records - drug charts, transfer of records, separation of records from patients.

c) Around misadministration - device design itself, complexity, variety of designs, confusion over correct use. 
Table 1

Self-medication errors.

\begin{tabular}{|c|c|}
\hline & Problems \\
\hline 1. & Self-medication error \\
\hline$P$ & Medication taken inappropriately \\
\hline S & Wrong drug administration \\
\hline$P$ & Patient unable to read labels \\
\hline I & $\begin{array}{l}\text { Patients confused by medication } \\
\text { names and/or appearance }\end{array}$ \\
\hline I & $\begin{array}{l}\text { Elderly patients unable to read } \\
\text { instruction on packs and/or } \\
\text { dispense medication from pack }\end{array}$ \\
\hline$P$ & $\begin{array}{l}\text { Patient error in frequency/ } \\
\text { dosage of medication }\end{array}$ \\
\hline
\end{tabular}

P\&L Patient confusion: failure to remove wrapper on suppositories, muddling up drugs; doses; timing

P\&L Removal of suppositories without removing wrapping

P Over-the-counter medication 'not harmful' often not seen as medication

I Non-compliance taking asthma medication i.e. Seretide, particularly under-dosing

P\&L Inadequate dosing of respiratory products via inhalers

I Operating inhalers: co-ordination (aerosols) and complex steps; high forces for children and infirm; when to renew; flow rates

I Accurately measuring liquid formulations (at home)

P Patient doesn't take medication when given - pills found in the bed, on the floor, etc.

I Inaccuracy of drug delivery in relation to diabetic insulin delivery

$\mathrm{P}$ Inappropriate or inadequate counselling of patient with regard to taking/handling medication

P Patient misunderstanding of relationship/interaction between prescribed and over-the-counter medicines

2. Self-medication error

P Reuse of insulin needles leads to hypo-dystrophy and/or needle breakage

$\mathrm{P}$ Inappropriate storage in home

$\mathrm{P} \quad$ Storage of medicines in patient's homes; child access

$\mathrm{P} \quad$ Storage of medicines in patient's homes; temperature control

P People having lots of different bottles of medication - out of date/current/not relevant - can take wrong one
Causes

Reading, understanding

Cannot read or understand leaflet inside package

Age (deteriorating eyesight means small letters hard to read); small lettering on ampoules; poor contrast on fonts; engraved/etched labelling can be hard to read

mpaired vision; small print on labels; poor durability of labels

Lack of standardisation

Lack of consideration of ergonomics issues related to older people.

Poor durability of computer printed labels affects legibility. Deficient instructions by GP regarding 'as required' medication; removal of tablets from original packs by patients.

Older patients; poor labelling; poor consulting; poly pharmacy; dangerous combination of potent drugs and low awareness patients. Also administration by family members acting as carers Inadequate user information. P.I.L. and package legibility Lack of knowledge/awareness

Forgetfulness; patient knows best (drug holidays); patient feels better; education

Over-complex design + operation requirements

Technical constraints; available technology; cost constraints

Lack of suitable delivery systems; unintentional misuse Lack of supervision, patient noncompliance, swallowing difficulties, patient can't handle dispensing format

Users not properly trained in administration of product; noncompliance due to patient error Knowledge; communication inadequacy; time resource; environmental inadequacy Over-the-counter (OTC) medicines often not perceived as potent

Storage, confusion, complicated regimes

Saving money

Lack of knowledge by patient

Packaging design

Poor instructions

People keep old medication, don't throw it away
Table 1 (continued)

\begin{tabular}{|c|c|c|}
\hline & Problems & Causes \\
\hline $\mathrm{I}$ & $\begin{array}{l}\text { Elderly confused patients with } \\
\text { several drugs failing to adhere to } \\
\text { medication instructions }\end{array}$ & $\begin{array}{l}\text { Forgetfulness; too much confusing } \\
\text { information; too many decisions; } \\
\text { poor/no aids to assist with correct } \\
\text { and timely dispensing }\end{array}$ \\
\hline $\mathrm{P}$ & $\begin{array}{l}\text { Identification of drugs (taken in } \\
\text { overdose) }\end{array}$ & $\begin{array}{l}\text { Drug names printed on the reverse } \\
\text { of blister packs are not readable } \\
\text { once the tablet is removed; drug } \\
\text { packs hoarded by patient }\end{array}$ \\
\hline $\mathrm{P} \& \mathrm{~L}$ & $\begin{array}{l}\text { Patient self medicating, takes } \\
\text { wrong drug from a number } \\
\text { prescribed }\end{array}$ & $\begin{array}{l}\text { Patient doesn't know what drugs } \\
\text { are for, cant read label, removes } \\
\text { blister from carton }\end{array}$ \\
\hline P\&L & $\begin{array}{l}\text { Patient takes same drug more } \\
\text { than once }\end{array}$ & $\begin{array}{l}\text { Brands plus generic version } \\
\text { available but patient doesn't realise } \\
\text { they are the same and takes both }\end{array}$ \\
\hline I & $\begin{array}{l}\text { Patients failing to comply with } \\
\text { prescribed treatment due to too } \\
\text { many medicines to remember }\end{array}$ & $\begin{array}{l}\text { Complicated drug regimes causing } \\
\text { confusion/error; variety of } \\
\text { packaging/poor quality } \\
\text { labels/instructions; }\end{array}$ \\
\hline 3. & Self-medication error & Access and packaging \\
\hline $\mathrm{P}$ & Access to packs and bottles & $\begin{array}{l}\text { Not getting the balance right } \\
\text { between impaired/elderly } \\
\text { requirements and child safety }\end{array}$ \\
\hline $\mathrm{P}$ & $\begin{array}{l}\text { Patients unable to manage } \\
\text { packaging }\end{array}$ & $\begin{array}{l}\text { Elderly; muscular/skeletal; } \\
\text { psychological/confusion; poor pack } \\
\text { design; prescriber unaware of user } \\
\text { needs/pack types }\end{array}$ \\
\hline $\mathrm{P}$ & $\begin{array}{l}\text { Older and arthritic patients } \\
\text { unable to open packaging - } \\
\text { container or blister strip } \\
\text { split off }\end{array}$ & $\begin{array}{l}\text { General Practitioner (GP) systems } \\
\text { ordering non pack size ( } 30 \text { when } \\
\text { comes in 28). Rules say if not a } \\
\text { calendar pack (no day/week on foil) } \\
\text { the exact quantity should be } \\
\text { supplied, hence odd } 2 \text { tablets } \\
\text { supplied, difficult to manipulate }\end{array}$ \\
\hline $\mathrm{P}$ & $\begin{array}{l}\text { Older people will get a third } \\
\text { party to open packaging and } \\
\text { leave open - can't open } \\
\text { 'child proof tops so leave off. } \\
\text { May lead to deterioration of } \\
\text { contents }\end{array}$ & $\begin{array}{l}\text { Manufacturers reluctance to think } \\
\text { of new ways of packaging }\end{array}$ \\
\hline 4. & Self-medication error & Information, knowledge \\
\hline $\mathrm{P}$ & $\begin{array}{l}\text { Patient/carer lack of knowledge } \\
\text { leads to errors in managing } \\
\text { medication in community - take } \\
\text { too much, too little, wrong time or } \\
\text { combination }\end{array}$ & $\begin{array}{l}\text { Lack of awareness/understanding } \\
\text { by presenter; unreadable } \\
\text { information in packaging }\end{array}$ \\
\hline $\mathrm{P}$ & $\begin{array}{l}\text { Incompatible or contrary } \\
\text { information supplied to patient by } \\
\text { healthcare professional - GP, } \\
\text { Pharmacist, nurse, Internet, } \\
\text { relative }\end{array}$ & Poor communications \\
\hline $\mathrm{P}$ & $\begin{array}{l}\text { Care provider not understanding } \\
\text { about the medicines they are } \\
\text { supervising/assisting in } \\
\text { administering }\end{array}$ & Lack of training/information sharing \\
\hline
\end{tabular}

Note: For Tables 1-7 the following key indicates which stakeholder group raised each problem. $(\mathrm{P}=$ primary care; $\mathrm{S}=$ secondary care; $\mathrm{P} \& \mathrm{~L}=$ purchasing and licensing; $\mathrm{I}=$ industry)

\subsection{Understanding patient issues}

The problem appeared to break down into complex interactions between risky situations, risky moments, risky items and risky users. Key areas or 'accident hotspots' were identified. These included:

- In the home, around problems associated with packaging, storage, remembering, reading, understanding, etc.

- In transfer/transit around changes in drugs, protocols, people, equipment, records, etc.

- Around the hospital bed and infusion lines, connectors, notes and record keeping, communication between staff, drug administration procedures, etc. 
Table 2

Prescription errors. $\begin{array}{ll}\text { 1. } & \text { Prescription error } \\ \text { P\&L } & \text { Prescription error }\end{array}$

I Poor handwriting/transcription errors/illegibility

P Wrong patient gets script

P Prescribing drugs outside normal experience

$\mathrm{P}$ Incorrect prescription because of confusion of generic names

P Misprescribing of drugs with similar names

P Ignoring decision support e.g. prescribing software etc

2. Prescription error

$\mathrm{P}$ Inappropriate information from drug company reps etc.

P Errors in communication with patients (by GPs and pharmacists e.g. on how to take inhalants)

P Interactions with over-the-counter Poor history taking by GPs products

P Audit trail for controlled drugs Drugs left in patients possession (once they have reached the patient) route for disposal are 'owned' by patient; no formal

- Where situations and equipment or medications are new or unfamiliar, and when people are working under pressure.

- Where information becomes 'non-sticky' and gets detached from patients, packaging, medication, or ineffectively or incompletely transferred, e.g. to pharmacists.

- In cases of mistaken identity related to names, packs, connectors, ampoules, infusion pumps, non-standard equipment and so on.

- In failures to effectively capture errors or information that is design-relevant.

- Where problems and causes are confused and conflated, especially around non-compliance and there is a tendency to blame - the patient or the manufacturer or the doctor or carer, rather than unravel the complex, interrelated chain of causes and resulting problems.

- Solving the major pack-associated problems for older people in their homes may also solve similar problems for other groups.

- Tackling the major problems for hospital staff and paramedics, associated with identifying medications once they are separated from their packs may solve similar problems for other less critical groups.

\subsection{Finding creative 'solutions'}

The generic issues and situations that had emerged from the previous workshop were fed back to the 'creative' workshop participants as a stimulus for the day.

One place to look for solutions is to identify common problems that occur in different forms and in different situations, and then select 'critical' users to work with (i.e. those most likely to experience or be associated with the more severe or extreme expressions of the problem.)

The capture method used at the creative workshop proved highly effective in terms of eliciting specific and detailed information about how and why problems occur at different locations. To facilitate this process a large drawing of the patient journey/
Table 3

Dispensing errors.

$\begin{array}{ll}\text { 1. } & \text { Dispensing error } \\ \text { P\&L } & \text { Wrong drug dispensed } \\ \text { P } & \begin{array}{l}\text { Dispensers/pharmacists } \\ \text { dispensing wrong medication } \\ \text { pack }\end{array} \\ \text { P } & \begin{array}{l}\text { Wrong medication/strength } \\ \text { supplied against GP/dental } \\ \text { prescription }\end{array} \\ \text { S } & \text { Wrong drug given in error }\end{array}$

P Mis-pick medicine

P\&L Dispensing/administration error

$\mathrm{S}$ Inconsistent colour/packaging of medication

I Incorrect product selection by nurse/pharmacist prior to administration

S Pack selection; All along the supply chain

I Sound-alike and look-alike names of medicines causing incorrect product selection

P Confusion of drug identity with multiple names for the same drug

2. Dispensing error

P Norton/Ivax - Atenolol $100 \mathrm{mg}$ prescribed for blood pressure; Azathioprine $50 \mathrm{mg}$ supplied (an immunosuppressant)

P Prochloperazine $5 \mathrm{mg}$ on prescription, Procyclidine $5 \mathrm{mg}$ supplied

P Wrong profiled insulin pen given to/used by patient -42 fast as opposed to 42 basal

P Tegretol anti-epileptic drugs - al forms and strengths have same coloured boxes

3. Dispensing error

P\&L Dispensing errors: incorrect selection; incorrect labelling; incorrect supply

P Mis-labelled medicine

P Dispensing Medications in the community; mislabelling by pharmacy/dispensing doctor

4. Dispensing error

$\mathrm{P}$ Stock control, out of date drugs

P Out of date fluids given - saline, dextrose
Wrong drug

Label not read correctly by healthcare practitioner (HCP); similarity in packaging; busy pharmacy; poorly written prescriptions

Design of packs conforming to manufacturers corporate identity despite different medications, dosage, strength; similar generic names causing confusion

Process control; pack design/clarity

Identical packaging by drug company of different drugs; Pharmacy stock constantly changing supplier Similar pack; word shape; similarity of drug name; distraction

Poor medicine labelling; poor pack design

Lack of direction centrally; importing

Similarity of labelling/packaging; lack of training/awareness

Design of packaging; shelving for storage

Difficulty in finding unique

nomenclature

Lack of clarity if the actual drug name on some packages - some very similar names used to identify different drugs

Specific confusions

Manufacturers pack design - same colour, size box, sit next to each other in continental drawer system typeface size where label applied is small - both white tablets so patient takes one before noticing difference

Norton/Ivax packaging is same colour, size, font and lie next to each other; corporate colour coding scheme focused on brand identity rather than product identity, colour now changed

Poor information on script; GP not giving enough information; pharmacist not asking; patient not realising difference

Manufacturer, and all their other products are in the same coloured packages

Mislabelling

Human failure; confusion: not reading label; misreading; choosing by sight (colour coding) Knowledge; Distraction; Label system shortcomings

Process control

Stock contro

Short shelf life of some products Staff under pressure have not carried out proper safety checks. Most fluid bags look the same, dates on fluids in small font not distinctive 
Table 3 (continued)

\begin{tabular}{|c|c|c|}
\hline 5. & Dispensing error & Incorrect supply to pharmacy \\
\hline $\mathrm{P}$ & Wrong supply to pharmacy & \\
\hline $\mathrm{P}$ & $\begin{array}{l}\text { Amiodarone } 200 \mathrm{~g} \text { supplied by } \\
\text { wholesaler (anti-arrhythmic for } \\
\text { heart) Trimethoprin } 200 \mathrm{~g} \\
\text { ordered (antibiotic) }\end{array}$ & $\begin{array}{l}\text { Packaging same colour; } \\
\text { manufacturers packaging designs } \\
\text { identical and same strength. Only } \\
\text { drug name differs; untrained staff } \\
\text { and language problems loading } \\
\text { automatic A-frame system }\end{array}$ \\
\hline$P$ & $\begin{array}{l}\text { Availability of some drugs, } \\
\text { changes in packaging and } \\
\text { presentation }\end{array}$ & Supply and distribution \\
\hline 6. & Dispensing error & Clinical trials \\
\hline$S$ & $\begin{array}{l}\text { Dispensing of active medication } \\
\text { for a clinical trial when placebo } \\
\text { medication called for }\end{array}$ & $\begin{array}{l}\text { Trial design; unfamiliarity; out of } \\
\text { hours; trial supplies }\end{array}$ \\
\hline
\end{tabular}

experience was prepared, and used as a trigger for discussion of 'site-specific' issues. Participants were open and very forthcoming, and the atmosphere of the group was one of collective participation and involvement.

Over 90 issues were gathered in little more than an hour of extensive and focused discussion, giving useful detail in relation to: care at home involving GP, community nurse etc.; the local pharmacy; the surgery and day-care centre; the rescue services; entering hospital; the operating theatre; intensive care; the ward; and patient aftercare. Examples of output are included in Table 8 (For full details see Cambridge, Surrey, RCA, 2004).

\subsubsection{Solution spaces}

Typically, after quite lengthy general discussion to establish a focus and priorities, the teams moved onto discussing very specific and in-depth problems. There was a strong sense of ownership of these by individuals and a practical desire to reach combined solutions to more than one problem. In several instances, such detailed information pointed to design solutions, for example:

- Paramedics repack ampoules in a handy (mixed) format using existing larger quantity packs - there was therefore scope for smaller volume supply or special containers designed for paramedics that give better visibility and identification.

- Information fails to transfer properly from one environment to another, for instance: ambulance drug records are hand written under pressure and using abbreviations/codes and are therefore often mistranscribed - scope for the use of 'peelable' barcodes in the recording of drug information in many situations including the home. These could be peeled off from medication packaging, or from a sheet and stuck to the patient record, allowing for accurate, swift and keyless transcription to computerised records.

- Patients, paramedics and other carers are often unaware of what medications are for - there was therefore scope to add this information to prescriptions and labels on dispensed drugs, as an aid to identification and a way of better informing patients, to be pointed out to patients at the pharmacy.

- Pharmacists who remember dispensing drugs from large quantity containers and counting tablets pointed out the extent to which they were other cues available to them that helped aid identification. For example, the smell of different drugs, their appearance, the feel of them to the fingers, the sound they made when poured out on the counter, the dust they produced and other factors provided near-subliminal information/ confirmation as to the identity of the medication. With modern packaging, not only were these subtle clues no longer available to the pharmacist, but the similarity and the proliferation of

Table 4

Administration errors.

1. Administration error

P Uncertainty of drug doses, especially in paediatrics

P Use of paediatric drugs in pre-hospital care - ambulance paramedics

S Error of drug dilution in paediatrics

$\mathrm{S} \quad$ Error in dose prescription and failure to identify this, resulting in incorrect drug being administered to child

P Standard doses for adults given to elderly people - with different rates of drug metabolism/absorption.

2. Administration error

P Misread prescription - dose drug etc.

P\&L Dispensing errors (personal) incorrect administration solution, dose, rate of administration

S Misreading of decimal point on prescription - nurse gives too much drug

$\mathrm{S}$ Confusion and delays in giving emergency drugs

P\&L Medication errors caused by 'human factors' e.g. fixation, routine, stress, poor processes

S Drugs wrongly prepared (concentrations)

S Wrong drug \pm wrong dose

S Miscalculation of prescribed dose

P\&L Administration erro increases risk of error

P Supply quantity is larger than normally carried on an ambulance/by a paramedic meaning drugs are often removed from a box and even put into other drug boxes

I Medicines being separated from their original containers/packaging prior to use

3. Administration error

$\mathrm{S}$ Nurse takes verbal instruction from doctor - incorrect medication given

$\mathrm{S} \quad$ Failure to give prescribed drug by nursing staff
Wrong dose/dilution

Different methods of calculating

doses - age, size, weight -

adult/child vary according to drug Environment is stressful, only two staff to complete multiple tasks, time constraints; draw up exact amounts of drugs Paediatric doses

Volume of workload/dependency of sick children on the drug

Misinterpretation, confusion Knowledge, training; distraction, personal issue; unclear direction, illegibility Poor labelling; not reading labels human error, prescription error

Change of name - adrenaline to epinephrine; staff too often unfamiliar with description of concentration e.g. 1:1000 etc. Lack of awareness; low levels of education/training; cultural issues 'way we do things round here'; poor standardisation; multiple variety in applications

Difficult to find preparation information and no info about how long to give drugs over; 'Information for patients' included in drug packaging is often inappropriate and does not include practical instructions.

Illegible prescription

Problems re interpretation of prescribing information and local documents/charts

Confusion around colour coding; poor labelling; small print; can't read in dark; similar drug names; mcg confused with mg; confusion over measures/ratios: $1: 1000,0.1 \%$, $1 \mathrm{mg} / \mathrm{ml}$

Some drugs supplied in dried or concentrated form needing dilution with saline or water

Supply quantity does not relate to normal pre-hospital doses

Convenience/speed; poor design/storage facilities/packaging

Information/communication Availability of doctor; agreement by nurse

Pressure of wards; prescription charts; organisation of one-off medication 
Table 4 (continued)

S Miscalculation of drug to be administered from a correct prescription

$\mathrm{S}$ Incorrect drug dispensed to patient

P Hand medicine to wrong patient

S Drug prescribed but wrong drug given to wrong patient

S Nurse fails to check patient name, patient confused and confirms (mishears) name given drug intended for another patient

4. Administration error Methotrexate

P\&L Methotrexate intended for weekly Lack of knowledge on the part of dosing, but patient takes it daily

S Oral weekly Methotrexate given daily

5. Administration erro

P\&L Administration error: rate; route

P Incorrect route of administration in emergency (resuscitation usually) situation or incorrect dosage

S Drug delivered by incorrect route (intrathecally rather than intravenously)

S Intravenous (IV) administration of Prepared infusion in solution bag drugs intended for another route

I Poor process control inexperienced staff being put into situations of risk (to patients) e.g. cytotoxic chemotherapy administration/ spinal procedures by junior hospital doctors

S Vincristine (chemotherapy agent) wrongly given intrathecally instead of intravenously. Patient dies.

$\mathrm{S}$ Vincristine administered intrathecally

S Administration of potent anticancer drugs (Vinca alkaloids) into central nervous system instead of intravenously

P\&L Accidental intrathecal injection of Vincristine

Inexperienced staff; staff in unfamiliar working environment

Unable to read prescription; not checking drug with patient Distraction; patient reaction violation of procedures or inadequate procedures Illegible handwriting; incorrect checking of drug chart

HCP about use of Methotrexate; lack of information to patient about how drug should be used Labelling, training, packaging, knowledge (lack of)

Route

Poor training/ignorance; pump used incorrectly; injection intravenously not intrathecally and vice versa; confusion - mis-supply of product and/or not reading label

Ampoules difficult to read - shiny small print on shiny glass ampoules especially in emergency situation. Complexity and small print of data sheets

Pre-prepared drugs not labelled virtually identical to normal intravenous solution Cultural; availability of personnel; lack of perceived risk

Many (extensive report published); Doctors in hospital are a surprisingly unregulated group in terms of strict working practices

Connection standards; unfamiliarity; accreditation

Failure to check medication carefully; staff exceeding their training and responsibilities; Interchangeable connectors

Multiple, but the ability to connect 'Luer ' syringe to cerebro-spinal fluid (CSF) access devices is one. If this were impossible this error couldn't happen

P\&L Misconnection of medical devices resulting in inappropriate administration of drugs, or failure to deliver drugs

6. Administration error

P\&L Mistake in administration of infused drug and/or user error in setting up or use of equipment generic problem often with no clear cause

P\&L Misuse/abuse of e.g. infusion devices, syringe drivers

Table 4 (continued)

P\&L Inappropriate drug delivery rates when using infusion pumps and similar devices. Results in over/under infusion

P\&L Lack of standardisation of devices - wide variety available potential for staff to use unfamiliar devices

I Incorrect administration of medicines due to lack of understanding of equipment e.g. syringe drivers/pumps

P\&L Drug administration errors due to Incorrect interpretation of incorrect interpretation of instructions and wrong device connected instructions; potential for differen types of medical devices to be connected allowing inappropriate drug delivery

7. Administration error Misconnection/delivery

$\mathrm{S}$ Interruption in life-sustaining drug The design of syringe drivers, some infusion reduce rate of delivery towards the end of the infusion; insignificant alarm noises - should alert nurses to nearing completion of infusion some sound like feed pumps.

$\mathrm{S} \quad$ Syringe becoming detached from Poor design syringe driver. Delivery of incorrect dose

P\&L Plunger of pre-filled syringe falls Human failure - poor technique; out as syringe is connected to intravenous cannula

lack of familiarity in use of glass syringes

I Patient 'plays' with drug delivery Non compliant patient - no effective device, resulting in drug build-up design response and subsequent overdose

proprietary and generic medications meant that it was increasingly difficult for pharmacists to correctly identify drugs. There is scope here for various design approaches, ranging from adding back visual and tactile cues to packaging to obliging manufacturers to add an additional warning indicator to packs that are regularly mistaken. Barcodes could also be used to address this issue, and the adding of information about what the prescription is for could help confirm the choice of medication in the pharmacy.

This process led to practical ideas for solutions, which included:

- A patient information system building on patient/doctor interaction and the recording of what their medication was prescribed for, as an aid to communication between e.g., patients and pharmacists;

- A national patient/drug information system that would give correct information and encourage trust between patient and prescriber/carer;

- Simple redesigns of line connectors to eliminate incorrect connections;

- A customised individual drug administration/packaging system to aid medication compliance, particularly for complicated regimes;

- Improved pack designs to keep information with medication, both inside and outside the pack, and to facilitate identification of drugs and their use;

- A simplified drug recognition/information system tailored to different users, e.g. patients; community carers and hospital nurses in the ward and in intensive care;

- Ways in which 'peelable' barcodes could be used to update patient records both in stressful situations like rescue, and in the ward and the home; and

- Ways in which smartcards can be used in hospitals, by paramedics and in the home, to check, monitor and reassure. 
Table 5

Information and records.
1. Information and records
$\mathrm{P}$ Continuity of care

$S \quad$ Inadequate information flows regarding errors/near misses

S Poor secondary/primary care communication re medication monitoring

P Different drug protocols used by different care

providers/ambulance services -

2. Information and records

S Medications not clearly prescribed on drug charts. Allergy box not completed

$S \quad$ Nurse fails to record drug as given on drug chart - another nurse assumes drug not given and gives further dose

3. Information and records

S Nurse and checker doing drug round with controlled drug checker called away by another patient - other nurse continues, gives wrong patient drug

S Nurses (usually) have a 2nd person check drugs dose/expiry date etc. Doctors don't. Generally they are subject to less regulated practice than nurses.

S Nurse tells doctor that he/she has junior doctor and senior nurse). Doctor ignores expertise and knowledge of nurse 'postcode care' prescribed wrong drug (usually
Continuity between sectors

Not all drugs are available in all places, meaning that a patient is moved from one location to another. Often a suitable range of medication is not available in care homes. Only a list of drugs, or their prescription chart may travel with a patient. Nationally: lack of co-ordinated system (that being piloted has changed direction and looks to become less effective than desired) locally: poor or poorly used systems, poor feedback, inappropriate management responses

Poor recording/transmission in the NHS; inadequate emphasis in medical training; shortage of staff e.g. clerical; inadequate use of modern technology Local paramedic steering committee

Drug charts

Doctors under heavy workload pressure

Work pressure; lack of compliance with protocol

\section{Checking in wards}

Work pressures; distraction; non-compliance with protocol

Long-standing cultural differences of the domain of nursing and medicine. Arrogance of some doctors

Culture, hierarchical relationship; individual personality
Table 6

Equipment and devices.

\begin{tabular}{ll}
\hline 1. & Equipment and devices \\
$\mathrm{P}$ & Needlestick injuries from used \\
& intravenous cannulae or lancets
\end{tabular}

Given the nature of the study, and the short space of time allotted to the workshop, none of these solutions were explored in depth, and the participants themselves rapidly came up with challenges and further issues. The solutions are not therefore proposed as viable as they stand, but the potential effectiveness of the process was well demonstrated.

One major obstacle encountered at the creative workshop was the lack of specific knowledge. Although the participants had no difficulty in outlining possible ways in which the problems might be tackled, they hit a barrier in arriving at solutions because of a lack of knowledge about the system itself, and how elements of it interact.

\section{Discussion}

\subsection{Stakeholder involvement}

The fact that a cross-section of stakeholders could be brought together at very short notice and with an attendance rate in excess of $90 \%$ demonstrates a significant degree of commitment to
P\&L Sharps injuries to medical staff

P\&L Disposal of sharps used in medication delivery - problems created by injuries to staff and patients

2. Equipment and devices

$\mathrm{S} \quad$ Nurse hands syringe to colleague to give injection - colleague thinks it is a clear fluid, in fact syringe empty

S A\&E department, minor procedure taking place. Nurse hands doctor $5 \mathrm{ml}$ syringe that he/she thinks is saline and is in fact Lignocaine. Doctor injects, the patient is fine but could have had cardiac arrest

S Antimicrobials diluted with $\mathrm{KCl}$ instead $\mathrm{NaCl}$

P\&L Lignocaine selected for flush rather than saline/water in theatres

S Giving the wrong drug on occasion to a patient

S Busy junior ward doctors being the only people eligible to give intravenously. Being in a hurry, giving the wrong drug to the wrong patient

S Over-pressured doctors with inadequate knowledge of individual patients

3. Equipment and devices

$\mathrm{S}$ Over infusion of drugs

4. Equipment and devices

P\&L Traumatic patient injury arising from inappropriate delivery of medical gases

Sharps related incidents

Administration of

intravenous/intramuscular drugs in sub-optimal environments; cost of 'needle safe' devices

Inappropriate disposal of used syringes, needles, etc. 're-sheathing' syringes Improper disposal of sharps after use, and injuries from accidents while sharps are in use

Confusion, mistaken identity

Attention/distraction; failure to check

Poor communication; poor labelling of syringes/equipment; lack of protocols

$\mathrm{KCl}$ kept in same place as $\mathrm{NaCl}$ ampoules look/feel similar writing small

Similarity of packaging; poor storage of drugs - small containers outside fully labelled packaging; poor lighting; emergency situation, rapid response required

Picking up the wrong syringe and failing to check the label properly. It is part of an automatic process, and if distracted it is easy to do, with multiple syringes in use.

Not enough time; not enough care: lack of protocols; over reliance on 1 person to give all IV (Intravenous)

Increased pressure/turnover; decreased junior doctor hours often compounded by transient nursing staff

Over infusion

Using incorrect infusion device, one that infuses over 1 hour instead of 24

Gases

Equipment poorly understood by users; poor manufacturer instructions; inadequate training

S Nitrous oxide given, not oxygen - Confusing equipment, doctor error death of child

5. Equipment and devices

$\mathrm{S}$ potential for contamination (accidental or deliberate) of volatile anaesthetic agents

Peculiar to anaesthesia At least two of the volatiles come in screw-top bottles and could be contaminated. Most of the vaporisers have a 'key-filler' system to prevent misfiling of a vaporiser, but on one of the newest vaporisers the system can be by-passed

6. Equipment and devices

I Drug companies are turning to proprietary delivery systems to differentiate their products in the market. This means that the patient may have a range of drugs in very simila containers/systems
Insufficient differentiation Insufficient differentiation of drug delivery systems due to: costs of retooling to differentiate drugs by design solutions, inventory costs, timescales and costs to evaluate system 
Table 7

Key problems/errors and causes.

\begin{tabular}{|c|c|c|}
\hline & Key problems/errors & Causes \\
\hline $\mathrm{P}$ & Similarity of names and packs & $\begin{array}{l}\text { Confusion; lack of differentiating } \\
\text { features; working under pressure; } \\
\text { the way medications are stored: } \\
\text { in pharmacies, on wards, in the home }\end{array}$ \\
\hline $\mathrm{P}$ & $\begin{array}{l}\text { Communication including } \\
\text { language and non-verbal }\end{array}$ & $\begin{array}{l}\text { Assumptions; working under } \\
\text { pressure; staffing changes; native } \\
\text { language and cultural factors; } \\
\text { hierarchical culture in NHS; } \\
\text { misinformation }\end{array}$ \\
\hline $\mathrm{P}$ & $\begin{array}{l}\text { Information provision is quirky, } \\
\text { not systematic }\end{array}$ & $\begin{array}{l}\text { Commercial influence; no central } \\
\text { system or single accredited source } \\
\text { of information; variations between } \\
\text { suppliers; information leaflets } \\
\text { protect against litigation rather than } \\
\text { provide the right information } \\
\text { inappropriate forms for different } \\
\text { users }\end{array}$ \\
\hline $\mathrm{P}$ & $\begin{array}{l}\text { Physical access to the contained } \\
\text { medications by professionals } \\
\text { and users/carers }\end{array}$ & $\begin{array}{l}\text { Pack design; patient ability; } \\
\text { conflicts with child and tamper } \\
\text { resistance; prompts repackaging of } \\
\text { drugs; problems with blister packs }\end{array}$ \\
\hline $\mathrm{S}$ & $\begin{array}{l}\text { Drug identification - difficulty } \\
\text { of ensuring use of } \\
\text { correct drug. }\end{array}$ & $\begin{array}{l}\text { Highlighted by Vincristine, } \\
\text { in particular due to severity of } \\
\text { outcome in the event of } \\
\text { misadministration, but also occurs } \\
\text { in the case of tablets and } \\
\text { ampoules. Causes include: } \\
\text { similarity of packaging; } \\
\text { repackaging; use of colours; } \\
\text { renaming of brands; changes of } \\
\text { medication name e.g. adrenaline } \\
\text { now ephedrine; label size and } \\
\text { legibility; using drugs in } \\
\text { difficult/stressful situations }\end{array}$ \\
\hline$S$ & $\begin{array}{l}\text { Lack of/inaccessibility of } \\
\text { systematic information about } \\
\text { causes that can be used } \\
\text { to inform solutions. }\end{array}$ & $\begin{array}{l}\text { Contingent workforce - temporary } \\
\text { staff; structure of nursing and } \\
\text { medical workforce; staff shortages - } \\
\text { changing hours; } \\
\text { frequency/severity of disciplinary } \\
\text { action; fear of litigation; complex } \\
\text { reporting systems; failure to share } \\
\text { information }\end{array}$ \\
\hline S & $\begin{array}{l}\text { Administration of drug by } \\
\text { wrong route }\end{array}$ & $\begin{array}{l}\text { Equipment; variation/lack of } \\
\text { variation; wrong route 'selected' by } \\
\text { giver; warning systems; individual } \\
\text { 'initiative' (purchasing adapters); } \\
\text { human error; poor communication; } \\
\text { reporting feedback mechanisms }\end{array}$ \\
\hline S & $\begin{array}{l}\text { Repetitive error in drug } \\
\text { administration. }\end{array}$ & $\begin{array}{l}\text { Prescription charts - legibility; } \\
\text { environment - distractions; failure } \\
\text { to follow protocols; poor verbal } \\
\text { communication; poor record } \\
\text { keeping; role of 'checker'; lack of } \\
\text { error reporting (blame culture); } \\
\text { staffing - experience, temporary, } \\
\text { skill mix; cultural aspects - } \\
\text { dr./nurse relationship; human error }\end{array}$ \\
\hline $\mathrm{P} \& \mathrm{~L}$ & $\begin{array}{l}\text { Packaging. labelling, } \\
\text { presentation, recognition. } \\
\text { Differentiation }\end{array}$ & $\begin{array}{l}\text { Size/shape; lack of specification } \\
\text { and testing against it; commercial } \\
\text { pressure; poor labelling, esp. } \\
\text { legibility; incorrect interpretation of } \\
\text { instructions }\end{array}$ \\
\hline P\&L & $\begin{array}{l}\text { Inadequate understanding of } \\
\text { how to use device. And lack } \\
\text { of understanding of } \\
\text { information about abuse. }\end{array}$ & $\begin{array}{l}\text { Design; complexity of devices; } \\
\text { variety of makes and models; } \\
\text { supporting information or lack of it; } \\
\text { human factors; lack of training; } \\
\text { poorly designed documents }\end{array}$ \\
\hline $\mathrm{P} \& \mathrm{~L}$ & $\begin{array}{l}\text { Environmentally aware design } \\
\text { solutions (lack of); taking the } \\
\text { demands of working situations } \\
\text { and stresses into account as } \\
\text { part of the design challenge. }\end{array}$ & $\begin{array}{l}\text { Lack of collaborative working }+ \\
\text { joined up thinking; distance } \\
\text { between industry and designers } \\
\text { and the actual care environment; } \\
\text { industry's need for differentiation; } \\
\text { tendency to look for accuracy } \\
\text { rather than suitability for purpose } \\
\text { as easier to quantify. }\end{array}$ \\
\hline
\end{tabular}

Table 7 (continued)

Key problems/errors Causes

\begin{tabular}{|c|c|c|}
\hline P\&L & $\begin{array}{l}\text { Awareness of secondary risks of } \\
\text { e.g. sharps, medical gases, } \\
\text { administration, equipment }\end{array}$ & $\begin{array}{l}\text { Lack of training; lack of risk- } \\
\text { awareness; over-complexity of } \\
\text { safety systems }\end{array}$ \\
\hline I & $\begin{array}{l}\text { Noncompliant } \\
\text { patient/carer/physician }\end{array}$ & $\begin{array}{l}\text { Patient: reluctance to take } \\
\text { medication; confusion; } \\
\text { forgetfulness; supervision; } \\
\text { carer/physician: training; } \\
\text { inappropriate expertise; } \\
\text { administration }\end{array}$ \\
\hline I & Confusion between medications & $\begin{array}{l}\text { Delivery systems not differentiated; } \\
\text { similar packs/labels; similar names; } \\
\text { elderly confused patients }\end{array}$ \\
\hline I & Information flow - lack of & $\begin{array}{l}\text { Records not with patient - main } \\
\text { problem; incorrect modality } \\
\text { prescribed; poor handwriting }\end{array}$ \\
\hline I & $\begin{array}{l}\text { Users override design safety } \\
\text { features }\end{array}$ & $\begin{array}{l}\text { Patient plays with device; } \\
\text { paramedics in emergency } \\
\text { situations; medication separated } \\
\text { from pack; cannot understand }\end{array}$ \\
\hline
\end{tabular}

addressing the issues of medication error and patient safety across the many sectors of the UK healthcare system. However, this was a small, self-selected group and therefore subject to potential sampling and other biases. The stakeholders participating had a wealth of detailed experience which throws fresh light on how and why errors occur. They were keen to improve practice and patient safety in their specific fields and have had much to contribute to the process. Overall, there is a real potential for the successful and cost-effective engagement of stakeholders in the process of error reduction and improving patient safety, and a willingness among the stakeholders to be part of that process. Small groups of designers and stakeholders working together in an informal setting can rapidly identify and explore problems and move towards solutions. However, more detailed information is required if solutions are to be effective and actually improve patient safety.

\subsection{Problem identification}

A wealth of anecdotal detail on aspects of medication error, especially in the community, emerged from creative, primary, secondary and patient support group sessions. The patient group identified a range of issues, from support (or lack of it) to medication delivery by carers, through information flow, checking of medication, especially on transfer from one sector or care environment to another, to the need for patients to take ownership of their health conditions and treatments. In general it was thought

Table 8

Issues at the local pharmacy.

Negative issues

- People are reluctant to take medicine due to stigma, etc.;

- There are problems associated with effectively communicating with patients;

- There is inconsistency between individual pharmacists;

- Patients can chose to go to any pharmacy and so errors occur and patients are confused by differing presentations of medications;

- Presentation forms change frequently even if the patient goes to the same pharmacist

- Changes also occur to brand, trade and official names of medications; and

- Self-medication problems occur incorrect dosing with eye or nose dropper - very difficult/impossible to get it right.

Positive issues

- Pharmacists act as a checking process (though this is impeded);

- Pharmacists share information between pharmacies from different chains;

- Pharmacists are undervalued but often visited first in the case of illness. 
that patients do not know enough about their medication. Issues of human error versus culture and practices arose in all workshops. There was particular emphasis on variations in protocols between providers/services/sectors; confusions about responsibility; stressful situations; hierarchical and autocratic behaviour; and conflicts of interests between industry and healthcare system.

Many interrelated factors contribute to the major instances of error, and these occur in many variations with there being no clear cut differentiation between problems and causes. This reflects the complexity of the overall problem, and the varying experiences and perceptions of different stakeholder groups. However, the stakeholder workshops were highly successful in identifying a broad range of issues and understanding the details behind them.

It would be interesting in future research to compare this approach with more traditional methods of identifying errors (see for example, Carayon, 2007).

\subsection{Robustness of workshop outputs}

The categories of user problems identified in Tables 1-7 were subsequently compared with results from a separate review of the literature (see Cambridge, Surrey, RCA, 2004). The comparison seemed to confirm that direct consultation with stakeholders is a rapid, effective and robust way of identifying problems and errors.

\subsection{Creative solutions}

The creative workshop generated many issues centred around specific healthcare environments. While covering the same territory as other workshops, these results are much richer from a design perspective, giving specific details of actual incidences, contexts and practices, with further depth of information emerging in the group working sessions. From a design perspective the richness of detail and the range of viewpoints and contexts described were both interesting and valuable. As a process, similar stakeholder workshops could help designers better understand the complexity and range of factors to be taken into account.

\section{References}

Audit Commission, 2001. A Spoonful of Sugar. Audit Commission, London. Bradford, L.P., Gibb, J.R., Benne, K.D. (Eds.), 1964. T-Group Theory and Laboratory Method: Innovation in Re-education New York. John Wiley \& Sons Inc.

Brown, J., 1989. The participation exercise: an outsider's view in life after the broadcasting bill. In: Miller, N., Norris, C. (Eds.), Proceedings of the 20th University of Manchester Broadcasting Symposium Manchester Monographs.

Brown, J., 1996. Community empowerment. In: Boud, D., Miller, N. (Eds.), Working with Experience-animating Learning. Routledge, London.

Brown, J., 1997. Unpublished reports for a DTI Skills Challenge Fund project investigating innovation in ten workers' co-operatives in London

Buckle, P., Clarkson, P.J., Coleman, R., Ward, J., Anderson, J., 2006. Patient safety, systems design and ergonomics, meeting diversity in ergonomics. Applied Ergonomics 37 (4), 491-500.

Buckle, P., Clarkson, P.J., Coleman, R., et al., 2003. Design for Patient Safety A System-wide Design-led Approach to Tackling Patient Safety in the NHS Design Council/Department of Health, ISBN 1841827657.

Cambridge, Surrey, RCA, 2004. Designing for Patient Safety. A Scoping Study to Identify How the Effective Use of Design Could Help to Reduce Medical Accidents. Cambridge Press, ISBN 0-9545243-0-6.

Carayon, P. (Ed.), 2007. Handbook of Human Factors and Ergonomics in Health Care and Patient Safety. Publ. CRC Press, ISBN 0805848851.

Clarkson, P.J., Buckle, P., Coleman, R., Stubbs, D., Ward, J., Jarrett, J., Lane, R., Bound, J., 2004. Design for patient safety: a review of the effectiveness of design in the UK health service. Journal of Engineering Design 15, 123-140.

Department of Health, 2001. Building a Safer NHS for Patients. Department of Health, London, UK.

Department of Health, 2004. Chief Pharmacist's Report, Building a Safer NHS for Patients: Improving Medication Safety. Department of Health, London, UK.

Miller, N., Brown, J., 1985. The Mini-economy, in Politics and Profits, April 1985

Miller, N., 1989. Personal Experience, Adult Learning and Social Research: Developing a Sociological Imagination in and Beyond the T-group Centre for Human Resource Studies. University of South Australia. p.104.

National Patient Safety Agency, 2005. Building as Memory: Preventing Harm, Reducing Risks and Improving Patient Safety. NPSA, London.

O'Brien, D., 1981. Designing systems for new users. Design Studies 2, 139-150.

Wilson, J., 1991. Design decision groups: a participative process for developing workplaces. In: Noro, K., Imada, A. (Eds.), Participative Methods. Chichester, John Wiley, pp. 81-96. 